Kokodzte, E. (2003) Arhitektura dlja real'noj zhizni. Iskusstvo, no 2 (526), [online] Available at: https://iskusstvo-info.ru/arhitektura-dlya-realnoi-zhizni/ (accessed: 01.03.2020) (In Russ.).

Fromm, Je. (2006) Zdorovoe obshbestvo. Moscow, AST. 539 p. (In Russ.).

Smithson, R. (1996) A Sedimentation of the Mind: Earth Projects. Smithson, R. The Collected Writings. California, University of California Press, Berkeley and Los Angeles. 389 p. Pp. 100-113.

Submission date: 29.05 .2020$.

Кожаринова Анна Ростиславовна - кандидат философских наук, доцент кафедры философии, культурологии и политологии Московского гуманитарного университета. SPIN-код РИНЦ: 8434-2370. Адрес: 111395, Россия, г. Москва, ул. Юности, д. 5. Тел.: +7 (499) 374-55-11. Эл. aApec: anna_adv@inbox.ru.

Kozharinova Anna Rostislavovna, Candidate of Philosophy, Associate Professor, Department of Philosophy, Cultural Studies and Political Science, Moscow University for the Humanities. RISC SPIN code: 8434-2370. Postal address: 5, Yunosti St., Moscow, Russian Federation, 111395. Tel.: +7 (499) 374-55-11. E-mail: anna_adv@inbox.ru

DOI: $10.17805 /$ zpu.2020.2.12

\title{
Ценностные ориентации поколений сотрудников и организационная культура библиотеки
}

\author{
Е. В. ГРАКОВА, М. В. МАСЛАКОВА \\ ТЮМЕНСКИЙ ГОСУДАРСТВЕННЫЙ ИНСТИТУТ КУЛЬТУРЫ, \\ Т. Г. ДОЛГАНОВА \\ ТЮМЕНСКИЙ ГОСУДАРСТВЕННЫЙ ИНСТИТУТ КУЛЬТУРЫ; \\ ФИЗИКО-МАТЕМАТИЧЕСКАЯ ШКОЛА, Г. ТЮМЕНЬ
}

В статье рассматриваются вопросы применения к анализу организационной культуры библиотеки теории поколений. Организационная культура библиотеки определяется как совокупность мировоззренческих представлений ценностных ориентаций, моделей поведения и взаимоотношений в коллективе, независимо от занимаемого места в библиотеке, разделяемых всеми ее членами.

В качестве ядра организационной культуры библиотеки рассматриваются ценности (личностные и профессиональные), оказывающие влияние на информационно-культурный капитал библиотеки. Для характеристики ценностных ориентаций рассмотрены некоторые положения теории поколений. Отмечается, что в современных библиотеках персонал состоит из представителей трех поколений: беби-бумеров, поколения $X$ и поколения $Y$. Указаны профессиональные ценности работников библиотек, их значимость в организационной культуре.

Изучение теории поколений имеет значение для построения и развития организационной культуры библиотек, обладающих разнородным составом сотрудников. Совершенствование организационной культуры библиотеки с точки зрения модернизации информационного профессионализма сотрудников и учета их ценностных ориентаций целесообразно в контексте теории поколений.

Ключевые слова: информационная культура, организационная культура библиотеки; ценностные ориентации; персонал библиотеки; поколения; поколение беби-бумеров; поколение $X$; поколение $Y$ 


\section{ВВЕАЕНИЕ}

Профессиональные библиотечные сообщества и библиотеки имеют сложное взаи1 модействие с современными информационными процессами, обусловленное трансформацией информационных отношений, развивается качественно новая модель информационной культуры специалиста, важнейшей исходной составляющей которой является әргономичное использование информации, информационных ресурсов и технологий организации. Именно «информационно-культурный» капитал становится основой конкурентного преимущества библиотеки. Желание современных специалистов работать в «бирюзовых» ${ }^{1}(\Lambda а л у, ~ 2016)$ библиотеках обусловлено не только привлекательностью места работы, но и осознанностью социальной ответственности за циркулирующую информацию в библиотеке, возможностью непрерывного образования и необходимостью совершенствования информационной культуры, ориентированной на разноформатные потребности общества. Библиотечно-информационным работникам важно ощущение гармонии между своими личными ценностями и ценностями библиотеки. Библиотеки, ориентированные на гармонизацию ценностей, являются примерами наиболее успешного развития.

Изучением системы ценностей занимается теория поколений. Представители исследователей, ее отстаивающих, утверждают факт общности ценностных ориентаций людей одного поколения, а также влияние их на поведение человека в процессе трудовой деятельности. Поскольку система ценностей является базовым компонентом и организационной культуры, попытаемся в рамках статьи решить вопрос о соотношении содержания организационной культуры библиотеки и ценностных ориентаций сотрудников библиотек как типичных представителей поколений беби-бумеров, Х и $\mathrm{Y}$.

\section{ОРГАНИЗАЦИОННАЯ КУАБТУРА БИБАИОТЕКИ}

Организационная культура может играть решающую роль в мобилизации всех ресурсов библиотеки на достижение целей, а может стать причиной ее стагнации. Вопросы, связанные с организационной культурой, носят междисциплинарный характер, а потому их изучением занимаются представители разных областей знания.

Существует множество определений организационной культуры, это: 1) система ценностей организации; 2) комплекс разделяемых членами коллектива норм, эталонов поведения; 3) отношение персонала к выполняемым обязанностям и пр. (Борисенок, 2006; Каменская, 2011; Кондратьев, 2011; Сметанина, 2018).

Предлагается следующая трактовка понятия: «организачионная культура библиотеки» - это совокупность мировоззренческих представлений, ценностных ориентаций, моделей поведения и взаимоотношений в коллективе независимо от занимаемой должности в библиотеке, разделяемые всеми ее сотрудниками. Особенности библиотечно-информационной деятельности создают неповторимость организационной культуры библиотеки. Это неочевидность миссии и целей библиотеки для пользователей и государства в целом, стереотип простоты работы в библиотеке и непрестижность этой профессии; проблема оценки качества предоставляемых услуг в библиотеке и обслуживания пользователей; общение с большим количеством читателей предполагает напряженный рабочий ритм, а также преобладание женского пола в рабочем коллективе, что влияет на социально-психологический климат. Все эти факторы позволяют нам увидеть специфику организационной культуры библиотеки. 
Организационная культура состоит из компонентов, уровней и признаков, без которых она не сможет функционировать и существовать в целом (рис. 1).

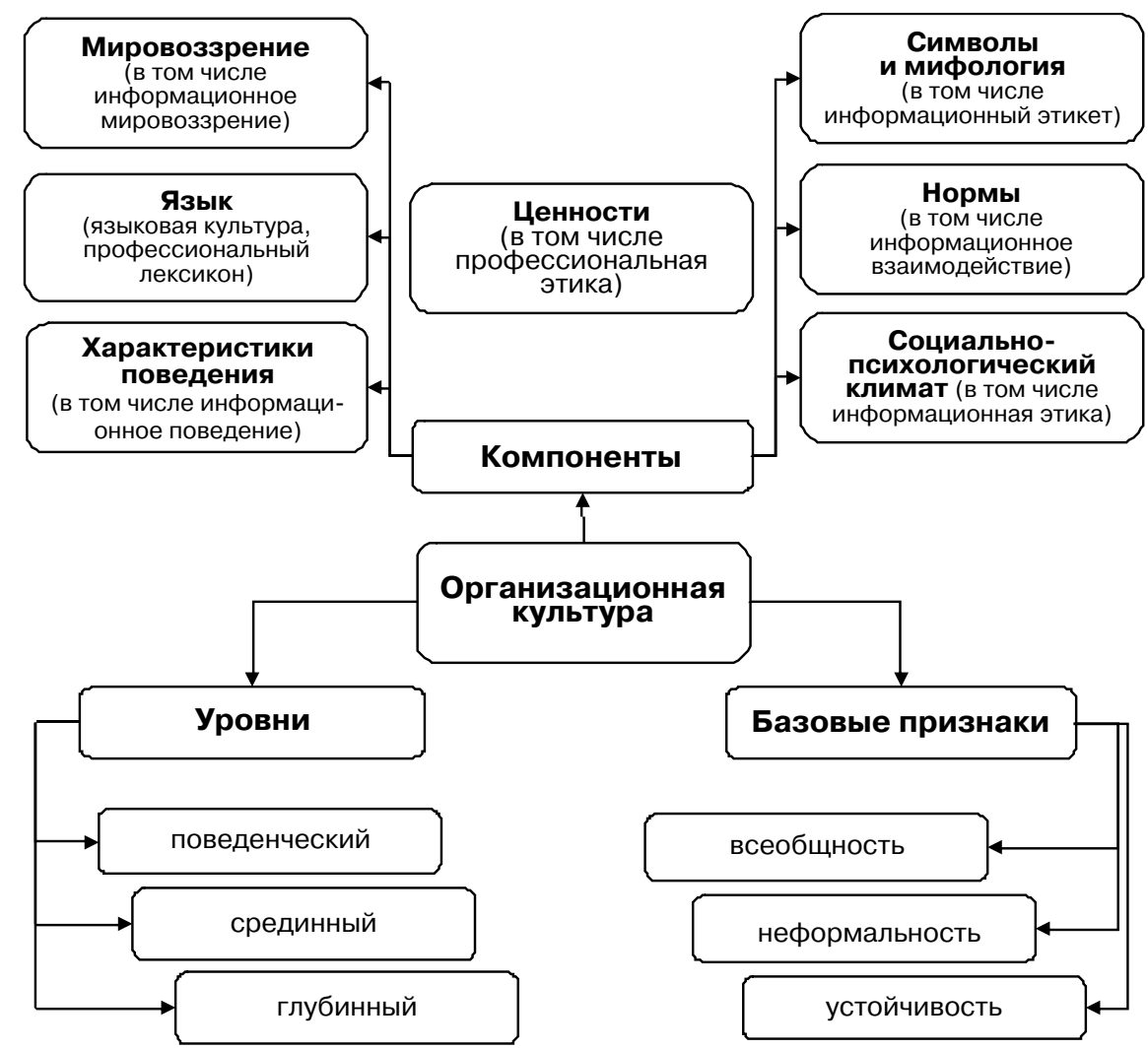

Рис. 1. Базовые признаки, уровни, компоненты организачионной культурь Picture 1. The basic signs, levels and components of organizational culture

Организационная культура библиотеки проявляется в стиле руководства, уровне ведения документационного оборота библиотеки, в принятых нормах поведения, разделяемых в библиотеке ценностей, верований. Она объединяет ценности и нормы, свойственные библиотеке, стиль и процедуры управления, концепции технологического и социального развития, задает пределы, в которых возможно уверенное принятие решений на каждом из иерархических уровней, возможности использования ресурсов организации в целом, ответственность, дает направления развития, регламентирует управленческую деятельность, способствуют идентификации членов с организацией (Каменская, 2011).

На любую организационную культуру сильное влияние оказывают личностные и профессиональные особенности персонала. Под персоналом библиотеки стоит понимать сотрудников учреждения, работающих в рамках трудового законодательства и обладающих определенными профессиональными компетенциями и личностными качествами. Основу профессиональных компетенций библиотечно-информационного работника составляет уровень его информационной культуры, рассмотрение кото- 
рой уместно применительно к деятельности организации, так как высокий уровень организационной культуры свидетельствует об информационной развитости субъектов организации. Поэтому особую актуальность приобретает вопрос о возможности воздействия на информационные процессы формирования и совершенствования информационной культуры сотрудников и их профессиональной компетентности посредством личностного воздействия. Все приобретаемые качества сотрудника ориентированы на общественно значимые ценности, которые формируются в течение длительного времени, но и они меняются в зависимости от внешних условий.

\section{ЦЕННОСТИ ПОКОАЕНИЙ}

Одним из компонентов организационной культуры являются ценности, составляющие ядро организационной культуры. Ценность - это весомость явлений, феноменов и объектов реалий, которую установило общество, социальные группы в соответствии со своими потребностями. Взгляды на жизнь в разные времена в обществе различаются, и то, что было нормой или даже правилом лет тридцать назад, теряет свою актуальность в наши дни. Трансформация жизненных устоев, политической ситуации в стране, культурных, социальных и материальных ценностей воздействует на мировоззрение человека. Совпадение важнейших ценностных ориентаций членов организации служит основой для сплоченности сотрудников, формирования единства взглядов и действий и, как следствие, повышения әффективности совместной деятельности.

Ценности являются мощным регулятором индивидуального и группового поведения персонала, который отображает жизненные принципы, цели организации и выбор личностью способов их реализации. Степень ясности и корректности индивидуальных ценностей проявляется в силе жизненной позиции личности, ее активности, инициативности, творчестве и внутренней мотивации к достижениям. Поэтому внимание к личностным и профессиональным ценностям работников целесообразно и с точки зрения совершенствования деятельности организации, полагает Т. М. Передерий (Корпоративная культура ... , 2002: 10).

Ценности влияют на улучшение информационного климата в коллективе, а также на совершенствование и формирование организационной культуры.

Особое значение для трактовки разности ценностей в трудовом коллективе имеет теория поколений. К ней ученые обращаются в случае необходимости объяснения трудового поведения людей, причин возникновения профессиональных конфликтов и т. д. В начале 1990-х гг. Н. Хоув и В. Штраус проанализировали «конфликт поколений» (Strauss, Howe, 1997; Исаева, 2011). Авторы обнаружили определенные периоды, когда большинство людей обладают сходными ценностями, в частности поведение человека зависит от того, в каких условиях он жил и воспитывался до 12-14 лет, так как до этого возраста у человека формируется собственная система ценностей.

В начале 2000-х гг. теория поколений для России была адаптирована специалистами проекта Rugenerations, руководителем которого является Е. Шамис (Шамис, Никонов, 2017ab). В классической теории новые поколения появляются примерно каждые 20 лет, а люди, рожденные на стыке двух поколений, относятся к так называемому эхо-поколению, которому свойственны ценности сразу нескольких поколений (Аолганова, 2018: 50). Согласно теории поколений, адаптированной для России, сосуществуют представители шести поколений: «величайшее поколение» (1900-1923); «молчаливое поколение» (1923-1943); «поколение беби-бумеров» (1943-1963); поко- 
ление Х («Икс») (1963-1984); поколение Y («Игрек») (1984-2000); поколение Z («Зэд») (с 2000 г.). Аля каждого поколения специалистами обозначены свойственные им ценности (Аолганова, 2016).

Как пишет Т. Г.Аолганова, теорию возрастных поколений полезно использовать не только в целях построения организационной культуры библиотеки и системы мотивации сотрудников, консультирования уже работающего персонала, соискателей, но и при библиотечно-информационном обслуживании, ориентируясь на их базовые ценности.

Основными представителями трудового ресурса в настоящее время являются представители поколения беби-бумеров, поколений X и Y. К беби-бумерам относят людей, родившихся в период с 1943 по 1963 г. Наименование поколение получило из-за послевоенного всплеска рождаемости. Термин «поколение $\mathrm{X}$ » предложили британский исследователь Аж. Аеверсон и голливудский репортер Ч. Хамблетт, а закрепил писатель А. Коупленд. Так называют людей, родившихся в период спада рождаемости в 1960-1965 гг.: они говорили о потере культурной связи с поколением беби-бумеров (Аолганова, 2016). Аля обозначения поколения людей, родившихся в период с 1979 по 2000 г., специалистами используются термины: «поколение Y», «миллениалы», поколение next и пр., характеризующиеся вовлеченностью в цифровые технологии.

Ценности этих трех поколений следующие: успех в виде наград, медалей, грамот и пр., оценивание работы, материальное благополучие, стимулирующие выплаты (поколение беби-бумеров); готовность к переменам, свобода выбора, глобальная информированность, техническая грамотность, индивидуализм, стремление постоянно пополнять свои знания, неформальность взглядов, поиск эмоций, прагматизм, надежда только на себя и равноправие полов (поколение X); свобода, развлечения, «гражданский долг», «мораль», «ответственность», наивность, умение подчиняться, немедленное вознаграждение, мода и бренды (поколение Ү) (рис. 2).

Поколение беби-бумеров - это люди 55-60 лет, консерваторы; для них имеет первостепенное значение уважение их статуса, подобающий внешний вид (соблюдение правил дресс-кода), стремление всегда быть первым, грандиозные планы, командная работа. Аля выстраивания положительных отношений с партнером, руководителем или коллегой из поколения беби-бумеров необходимо соотносить свою деятельность с его личными интересами и с интересами библиотеки, подразделения, отдела и т. п., участвовать в развитии библиотеки во временной долгосрочной перспективе (10-20 лет), работать на энтузиазме, иметь доверительные командные отношения, присутствие формального и неформального общения, при контакте с беби-бумером советоваться с ним, исключить слово «проблема», заменять его синонимами (например, «трудность») и употреблять слова «модно», «современно», «актуально», «в новинку» («Читать модно!», «Новинки библиотеки», «Современное состояние деятельности библиотеки» и т. А.).

Аевиз поколения $X$ (средний возраст 56-35 лет) - «вся наша жизнь - борьба». Они уже замещают поколение беби-бумеров на руководящих должностях в библиотеке. Аля представителя этого поколения имеет значение признание его как личности, неформальность общения, равноправие. Сегодня в связи с финансированием сферы культуры по остаточному принципу наибольшее распространение приобрели награды морального характера (грамоты, благодарности), но «Х» это не мотивирует, для них большей ценностью является возможность выбора, а также самостоятельность, самодостаточность. Поэтому руководителям библиотек в работе с «иксами» следует четко прописывать систему правил, последствий за их нарушения 


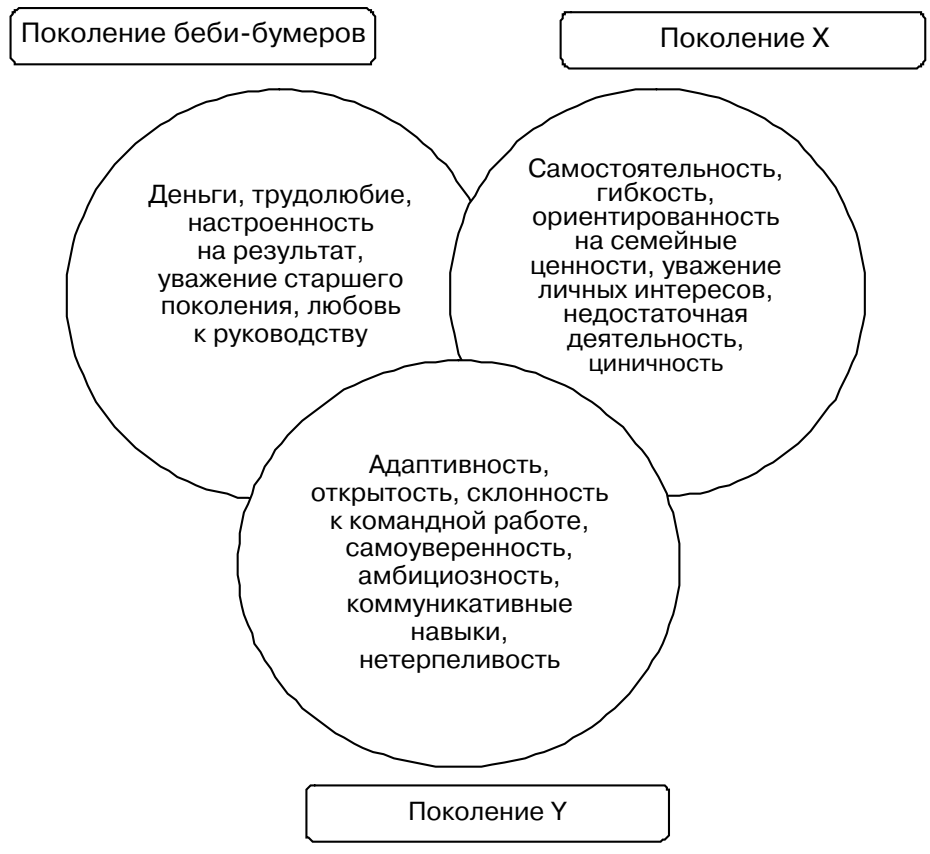

Рис. 2. Модель учета профессиональньх иенностей (поколение беби-бумеров, поколение $X$, поколение $Y$ )

Picture 2. The professional values accounting model

(Baby Boomer Generation, Generation X, Generation Y)

и поощрений за достижения. В противном случае «Х» будут стремиться выйти за пределы норм.

Представители поколения Y (средний возраст 35-18 лет) через несколько лет займут руководящие должности современной истории. В библиотечной сфере в настоящее время идет процесс обновления кадров, в первую очередь для продвижения библиотечно-информационных продуктов и услуг современными средствами. Аля плодотворного сотрудничества с представителями поколения Y необходимо предоставлять им максимально точную информацию о предстоящем фронте работ, привлекать во все направления работы библиотеки.

Стоит отметить, что для всех поколений важны, например, такие ценности, как семья, любовь, уважение соратников, желание работать с сильным лидером, стремление к знаниям, готовность обучаться, оперативная и объективная обратная связь.

Теорию поколений давно применяют в зарубежных странах при трудоустройстве на работу, исходя из ценностных ориентаций, присущих тем или иным поколениям. Руководитель при приеме на работу оценивает не только их знания и умения, но и, изучив их ценности, знает, как найти подход к каждому из поколений, какими качествами они обладают.

В процессе управления персоналом руководителю библиотеки рекомендуется находить дифференцированный подход к людям разных поколений, опираясь на их профессиональные ценности, такие как уважение к труду, распределение труда и отдыха, отношение к трудовой дисциплине. 


\section{ЗАКАЮЧЕНИЕ}

О. Э. Башиной, Е. С. Васютиной, $\Lambda$. В. Матраевой обозначены тенденции поведенческой модели на рынке труда, который постепенно наполняет поколение Z, родившееся после 2000 г.: 1) отсутствие концентрации и глубины проработки вопросов; 2) отсутствие долгосрочных трендов, минимальный горизонт планирования; 3) изменение поведенческой мотивационной модели; 4) установка на гедонизм, в том числе и в трудовой деятельности; 5) автономизация личности и индивидуализм; 6) дезориентация норм сосуществования на единой территории в связи с виртуализацией среды; 7) боязнь «обычной» жизни без спонтанности, переживаний и впечатлений; 8) пассивность в отношении к собственному здоровью (Башина, Васютина, Матраева, 2018: 138-139). Обозначенные тенденции стоит учитывать при стратегическом управлении персоналом библиотеки.

В российской практике управления персоналом постепенно внедряется ценностно-ориентированный подход к управлению персоналом разных возрастов. Как и любая теория, теория поколений имеет своих единомышленников и противников, последние утверждают, что всем поколениям характерны традиционные ценности и антиценности. Например, для людей любых поколений важны семья, любовь, уважение, возможность работать с сильным лидером, но лояльность людей разных возрастов зависит от контекста (например, время, проведенное на работе, зависит не от возраста сотрудника, а от уровня занимаемой им должности).

Итак, изучение теории поколений имеет большую значимость для построения и развития организационной культуры в крупных библиотеках, достижения стратегических задач библиотек, повышения эффективности деятельности и дучшей адаптации к внешней и внутренней среде.

В процессе управления персоналом руководителю библиотеки рекомендуется находить дифференцированный подход к людям разных поколений, опираясь на их профессиональные ценности, такие как уважение к труду, распределение труда и отдыха, отношение к трудовой дисциплине.

Изучение теории поколений целесообразно для построения и развития организационной культуры библиотеки с точки зрения совершенствования информационного профессионализма сотрудников и учета их ценностных ориентаций. Связующим звеном в библиотеке является коллектив, от него зависит работа по достижению поставленных целей. Руководителям библиотек рекомендуется совершенствовать организационную культуру через персонал: создавать спокойную, психологически комфортную обстановку в библиотечных коллективах, оценивать способности сотрудников и давать поручения, исходя из их ценностных ориентаций, прививать уважение к библиотечной профессии, замечания высказывать в корректной форме, организовывать досуг персонала, способствовать развитию информационной культуры специалистов, «являющейся основой профессиональной составляющей, обеспечивающей качество профессиональной деятельности и самореализацию личности» (Маслакова, 2017: 115). Аля библиотечно-информационных работников свойственны информационное мировоззрение, профессиональные и личные ценности, которые рекомендуется учитывать для совершенствования организационной культуры; при трудоустройстве, определении зон ответственности, делегировании полномочий; мультиформатной коммуникации; реализации профессиональных компетенций. 


\section{ПРИМЕЧАНИЕ}

1 «Бирюзовые организации» - те, которые предоставили своим сотрудникам свободу в принятии решений; ушли от привычной иерархичной системы управления, сделали ее максимально плоской; постарались сделать своих сотрудников счастливыми.

\section{СПИСОК АИТЕРАТУРЫ}

Башина, О. Э., Васютина Е. С., Матраева А. В. (2018) Трансформация экономической и трудовой модели поведения современной молодежи в условиях становления цифрового общества // Знание. Понимание. Умение. № 3. С. 133-145. DOI: 10.17805/zpu.2018.3.12

Борисенок, А. $\Lambda$. (2006) Понятие организационной культуры как аналог корпоративной культуры // Научно-технический вестник Санкт-Петербургского государственного университета информационных технологий, механики и оптики. № 24. С. 127-133.

Аолганова, Т. Г. (2016) Теория поколений: пути применения в библиотечной практике // Молодые в библиотечном деле. №9. С. 64-68.

Аолганова, Т. Г. (2018) Теория поколений в контексте общества потребления // Вестник Московского института государственного управления и права. № 1. С. 49-52.

Исаева, М. А. (2011) Поколения кризиса и подъема в теории В. Штрауса и Н. Хоува // Знание. Понимание. Умение. № 3. С. 290-295.

Каменская, И. Н. (2011) Организационная культура как основа конкурентоспособности библиотеки // Научно-техническая информация. № 2. С. 23-29.

Кондратьев, Э. (2011) Организационная культура: понятие, механизм и методы управления // Проблемы теории и практики управления. №11. С. 56-64.

Корпоративная культура и персонал библиотеки (2002) / сост. Т. М. Передерий. Мурманск : б. и. 18 с.

Малу, Ф. (2016) Открывая организации будущего / пер. с англ. яз. В. Кулябиной. М. : Манн, Иванов и Фербер. 610 с.

Маслакова, М. В. (2017) Формирование общепрофессиональной компетенции выпускника: место и роль информационной культуры в образовательном процессе вуза // Инновации в образовании. № 4. С. 115-123.

Сметанина, М. А. (2018) К вопросу о соотношении понятий «организационная культура» и «корпоративная культура» // Гуманитарная парадигма. № 3 (6). С. $63-69$. $140 \mathrm{c}$.

Шамис, Е., Никонов, Е. (2017а) Теория поколений. Необыкновенный Икс. М. : Синергия.

Шамис, Е., Никонов Е. (2017b) Теория поколений. Стратегия Беби-бумеров. М. : Синергия. 255 с.

Strauss, W., Howe, N. (1997) The Fourth Turning: An American Prophecy - What the Cycles of History Tell Us About America's Next Rendezvous with Destiny. New York : Broadway Books. 382 p.

Аата поступления: 01.11.2018 2.

\section{VALUE ORIENTATIONS OF GENERATIONS OF EMPLOYEES \\ AND LIBRARY ORGANIZATIONAL CULTURE \\ E. V. GRAKova, M. V. MASLAKOVA \\ TYUMEN StATE INSTITUTE OF CULTURE \\ T. G. DOLGANOVA \\ Tyumen State Institute of Culture; Physics and Mathematics School}

The article considers the issues of applying the theory of generations to the analysis of the library organizational culture. The organizational culture of the library is defined as a complex of worldview insights, value orientations, behavior models and relationships in a team regardless of the place in the library and shared by all its members. 
As the core of the library organizational culture the authors consider the values (personal and professional) that affect the informational and cultural capital of the library. To characterize value orientations, some provisions of the theory of generations are analyzed. It is pointed out that modern libraries employ representatives of three generations: Baby Boomers, Generation X, and Generation Y. The authors indicate the professional values of library staff, their importance in organizational culture.

The study into the theory of generations is important for the construction and development of the organizational culture of libraries with heterogeneous staff. Improving the organizational culture of the library in terms of modernizing the information professionalism of employees and taking into account their value orientations is appropriate in the context of the theory of generations.

Keywords: information culture; organizational culture of library; value orientations; library staff; generations; Baby Boomer Generation; Generation X; Generation Y

\section{REFERENCES}

Bashina, O. E., Vasiutina, E. S. and Matraeva, L. V. (2018) Transformatsiia ekonomicheskoi i trudovoi modeli povedeniia sovremennoi molodezhi v usloviiakh stanovleniia tsifrovogo obshchestva. Znanie. Ponimanie. Umenie, no. 3, pp. 133-145. DOI: 10.17805/zpu.2018.3.12 (In Russ.).

Borisenok, A. L. (2006) Ponjatie organizacionnoj kul'tury kak analog korporativnoj kul'tury. Nauchno-tebnicheskij vestnik Sankt-Peterburgskogo gosudarstvennogo universiteta informacionnyb tebnologij, mebaniki i optiki, no. 24, pp. 127-133. (In Russ.).

Dolganova, T. G. (2018) Teoriia pokolenii v kontekste obshchestva potrebleniia. Vestnik Moskovskogo instituta gosudarstvennogo upravleniia i prava, no. 1, pp. 49-52. (In Russ.).

Dolganova, T. G. (2016) Teoriia pokolenii: puti primeneniia v bibliotechnoi praktike. Molodye $v$ bibliotechnom dele, no. 9, pp. 64-68. (In Russ.).

Isaeva, M. A. (2011) Pokoleniia krizisa i pod»ema v teorii V. Shtrausa i N. Khouva. Znanie. Ponimanie. Umenie, no. 3, pp. 290-295. (In Russ.).

Kamenskaia, I. N. (2011) Organizatsionnaia kul'tura kak osnova konkurentosposobnosti biblioteki. Nauchno-tekbnicheskaia informatsiia, no. 2, pp. 23-29. (In Russ.).

Kondrat'ev, Je. (2011) Organizacionnaja kul'tura: ponjatie, mehanizm i metody upravlenija. Problemy teorii i praktiki upravlenija, no. 11, pp. 56-64. (In Russ.).

Korporativnaia kul'tura i personal biblioteki (2002) / comp. by T. M. Perederii. Murmansk, s. n. 18 p. (In Russ.).

Lalu, F. (2016) Otkryvaja organizacii budushbego / perevod s anglijskogo jazyka V. Kuljabinoj. Moscow, Mann, Ivanov i Ferber. 610 p. (In Russ.).

Maslakova, M. V. (2017) Formirovanie obshcheprofessional'noi kompetentsii vypusknika: mesto i rol' informatsionnoi kul'tury v obrazovatel'nom protsesse vuza. Innovatsii v obrazovanii, no. 4, pp. 115-123. (In Russ.).

Smetanina, M. D. (2018) K voprosu o sootnoshenii ponjatij «organizacionnaja kul'tura» i «korporativnaja kul'tura» Gumanitarnaja paradigma, no. 3 (6), pp. 63-69. (In Russ.).

Shamis, E., Nikonov E. (2017a) Teorija pokolenij. Neobyknovennyj Iks. Moscow, Sinergija. 140 p. (In Russ.).

Shamis, E., Nikonov, E. (2017b) Teorija pokolenij. Strategija Bebi-bumerov. Moscow, Sinergija. 255 p. (In Russ.).

Strauss, W. and Howe, N. (1997) The Fourth Turning: An American Prophecy - What the Cycles of History Tell Us About America's Next Rendezvous with Destiny. New York, Broadway Books. 382 p.

Submission date: 01.11 .2018

Гракова Елена Владиславовна - кандидат педагогических наук, доцент кафедры библиотечно-информационной деятельности Тюменского государственного института культуры. Ад- 
рес: 625003, Россия, г. Тюмень, ул. Республики, д. 19. Тел.: +7 (3452) 29-70-49. Эл. адрес: elena_grakova@mail.ru

Маслакова Мария Владимировна - кандидат педагогических наук, доцент, доцент кафедры библиотечно-информационной деятельности Тюменского государственного института культуры. Адрес: 625003, Россия, г. Тюмень, ул. Республики, д. 19. Тел.: +7 (3452) 29-70-49. Эл. aspec: mary_nosoreva@mail.ru

Аолганова Татьяна Геннадьевна - магистрант 1-го курса направления подготовки «Библиотечно-информационная деятельность» Тюменского государственного института культуры; библиотекарь Физико-математической школы. Адрес: 625003, Россия, г. Тюмень, ул. Республики, д. 19. Тел.: +7 (3452) 33-91-72. Эл. адрес: dol.tanya96@mail.ru

Grakova Elena Vladislavovna, Candidate of Pedagogy, Associate Professor, Department of Library and Information Activity, Tyumen State Institute of Culture. Postal address: 19, Respubliki St., Tyumen, Russian Federation, 625003. Tel.: +7 (3452) 29-70-49. E-mail: elena_grakova@mail.ru

Maslakova Mariya Vladimirovna, Candidate of Pedagogy, Associate Professor, Associate Professor, Department of Library and Information Activity. Tyumen State Institute of Culture. Postal address: 19, Respubliki St., Tyumen, Russian Federation, 625003. Tel.: +7 (3452) 29-70-49. E-mail: mary_nosoreva@mail.ru

Dolganova Tatyana Gennadyevna, Graduate Student, academic programme "Library and Information Activity", Tyumen State Institute of Culture; Librarian, Physics and Mathematics School. Postal address: 19, Respubliki St., Tyumen, Russian Federation, 625003. Tel.: +7 (3452) 33-91-72. E-mail: dol.tanya96@mail.ru 